\title{
Hearing Loss Revealing A Squamous Cell Carcinoma Of External Auditory Canal In A Post- Irradiated Patient For Nasopharyngeal Carcinoma: A Case Report
}

\author{
B. Merzouqi, Zakaria Chafiki*, K. Salama, S. Rouadi, A. Abada, M. Roubal and M. Mahtar \\ Hospital University, Morocco
}

Submission: February 21, 2017; Published: March 16, 2017

"Correspondence Address: Zakaria Chafiki, Rue 266, Num 48, haymoulayabdellah, Casablanca, Hospital University, Morocco, Email: zakaria.chafiki@gmail.com

\begin{abstract}
Background: Primary Carcinoma of EAC is a rare disease accounting for less than $2 \%$ of head and neck cancers and has an annual incidence of around 1 per million populations. EAC carcinoma in post-irradiated nasopharyngeal carcinoma (NPC) patients occurs with an incidence of approximately $0.15 \%$. It arises from the external ear and spreads to the temporal bone and surrounding sites. Although its rarity, it is a life threatening disease with practically a poor constant prognosis. Primary EAC carcinoma can occur with no specific symptoms. Aggressive surgery with postoperative radiation remain the usual treatment until now. We report a rare case of a squamous cell carcinoma (SCC) of EAC revealed by a progressive hearing loss as first presentation of the disease in a post-irradiated woman for NPC.
\end{abstract}

Results: a 47-year-old female with a past medical history of nasopharyngeal carcinoma treated with chemoradiation therapy, presented for repeated left-sided purulent ear discharge and progressive hearing loss. Otoscopic examination revealed a tissue mass filling the left EAC. CT scan revealed a soft tissue density process filling the EAC, encroaching upon the tympanic cavity and coming into contact with the handle of the malleus with no ossicular lysis nor EAC walls erosion. The biopsy of the mass was consistent with EAC SCC. The patient underwent lateral temporal bone resection with homolateral superficial parotidectomy and selective neck dissection and completed by an adjuvant external radiation therapy (RT).

Conclusion: Post-irradiation EAC SCC has similar symptoms and invades similar regions as its primary counterpart. This entity is usually discovered in the early stage in post-irradiated EAC SCC patients comparing to the primary EAC SCC. Aggressive surgical treatment is strongly recommended, but adjuvant radiotherapy for early stage EAC SCC should be provided cautiously to prevent further radiation induced complications.

Keywords: External Auditory Canal; Nasopharyngeal Carcinoma; Post-Irradiated Tumor; Squamous Cell Carcinoma; Temporal Bone Resection; Radiotherapy

\section{Introduction}

Primary Carcinoma of EAC (external auditory canal) is a quite rare disease accounting as a cause of 1 in 5000-15,000 ear complaints [1]. It represents less than $2 \%$ of head and neck cancers and has an annual incidence of around 1 per million populations [2,3]. It arises from the external ear and spreads to the temporal bone and surrounding sites. Periauricular soft tissues, parotid gland, temporomandibular joint and mastoid are the common sites of tumor progression. The carotid canal jugular foramen, dura, middle and posterior cranial fossae are invaded in advanced stages $[3,4]$. Despite being extremely rare, EAC carcinoma is a life threatening tumor given its aggressive behavior. EAC carcinoma in post-irradiated NPC patients occurs with an incidence of approximately $0.15 \%$ [5], which is much higher than the incidence of primary EAC carcinoma among the general population. Many patients present with non-specific signs of chronic inflammation or infection which make detection and diagnosis of this malignant tumor difficult and the surgical management more challenging and risky [6]. The complex anatomicallocation and the susceptibility of tumor extension to contiguous tissues within a limited space make it complicated for surgery to achieve tumor-free margins [7]. Although several treatment modalities have been described in the literature, there 


\section{Cancer Therapy \& Oncology International Journal}

is a lack of consensus as to the best treatment, mainly due to the absence of prospective randomized studies [8]. Aggressive surgery with postoperative radiation therapy [RT] remain the Case Report usual treatment so far [9]. In this study, we report a rare case of EAC SCC in a post irradiated female revealed by a hearing loss which makes it an unusual presentation of the disease.

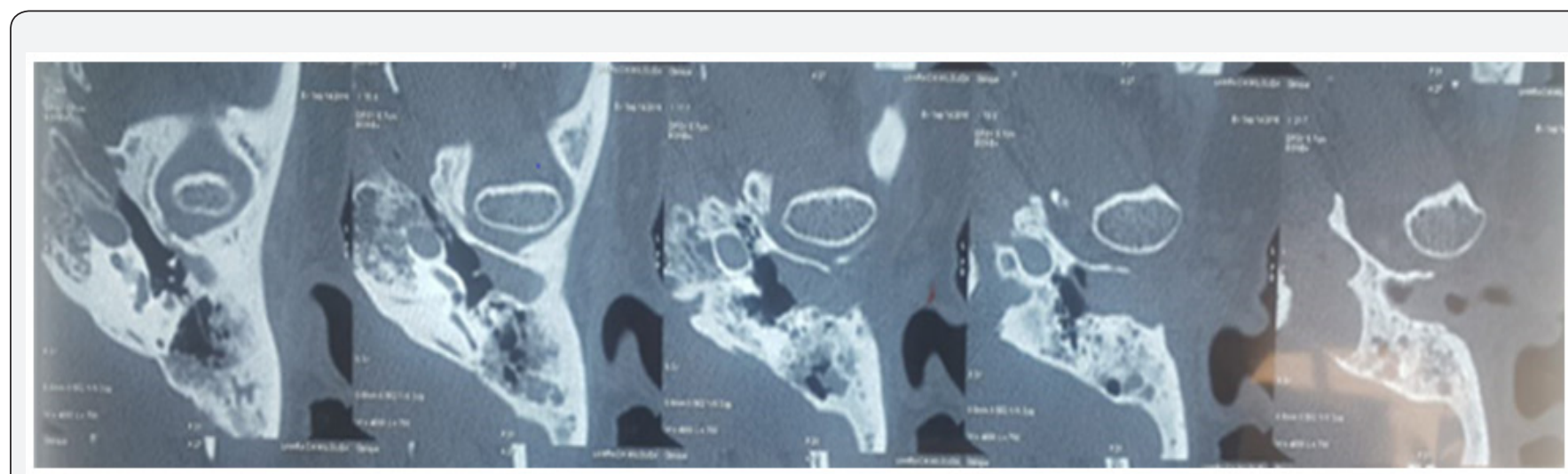

Figure 1: Temporal bone CT scan -axial sections- a soft tissue density process filling the EAC (polyp), encroaching upon the tympanic cavity and comes into contact with the handle of the malleus with no detectable ossicular lysis nor EAC walls erosion, with a partial filling of the mastoid cells.

A 47-year-old Moroccan female with a past medical history of NPC [2009] treated with chemoradiation therapy, presented to the ENT department of University hospital of CASABLANCA for repeated left ear purulent discharge over the past 6 months and a progressive hearing loss. Otoscopic examination revealed a tissue mass filling the left EAC. Temporal bone CT scan revealed a soft tissue density filling the EAC [polyp], enhancing after injection of contrast product. The tissue process encroaches upon the tympanic cavity and comes into contact with the handle of the malleus with no detectable ossicular lysis nor EAC walls erosion (Figure 1). The biopsy of the mass was consistent with squamous cell carcinoma of the left EAC. The patient underwent lateral temporal bone resection with homolateral superficial parotidectomy and neck dissection. Anatomopathological examination of the specimen substantiated a well differentiated keratinizing and infiltrating squamous cell carcinoma of the left EAC. Resection margins were affected and parotid specimens were healthy. The surgical management was completed by adjuvant external radiotherapy. Immediately in postoperative check-up, the patient presented left peripheral facial palsy [House III] (Figure 2). One year follow-up, the patient lives with no signs of recurrence.

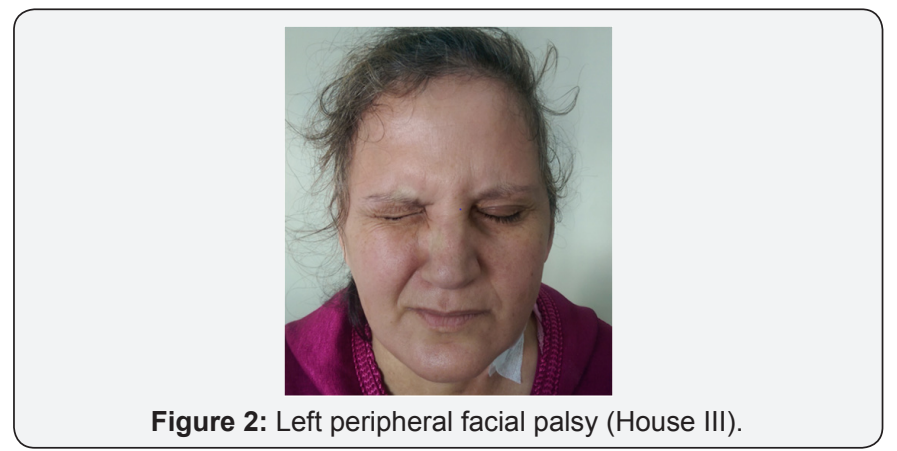

\section{Discussion}

Primary Carcinoma of EAC is a quite rare disease entity accounting as a cause of 1 in 5000-15,000 ear complaints [1]. It represents less than $2 \%$ of head and neck cancers and has an annual incidence of around 1 per million populations [2,3]. Squamous cell carcinoma [SCC] constitutes $82 \%$ of the tumors involving the auditory canal, middle ear, and mastoid [10] while adenoid cystic carcinoma [ACC] is seen only in $6-10 \%$ of all cases [11]. Chronic suppurative otitis media and previous irradiation are thought of as etiological factors [12]. This tumor usually occurs in the 5 th-7th decade of life $[13,14]$ with a slight male preponderance. Primary EAC carcinoma shows no specific symptoms, besides, they are occult during the early stage, which makes early diagnosis very difficult with otorrhea [50-90\%] being the most common reported symptom in various series followed by pain, hearing loss and mass the auditory canal [11]. Facial nerve palsy at presentation has been reported variably indifferent series in $16-50 \%$ of patients [15]. This tumor has always had a very poor prognosis given its aggressive nature and the susceptibility to spread along vascular and neural pathways [16]. The main cause of death is, usually, aggressive local recurrence [17].

The post-irradiated EAC carcinoma has been infrequently reported [18-25]. Lo et al. [5] reported that the incidence of EAC carcinoma in the post-irradiated NPC population was 1000 times greater than the reported incidence of primary EAC carcinoma in the general population. The post-irradiated EAC SCC shows no special symptoms compared with its primary counterpart. Our patient complained of a progressive hearing loss with a repeated purulent ear discharging over 6 months with a latency period of 6 years from the first cure of RT which is much lower than the period reported in others studies [5,25]. 


\section{Cancer Therapy \& Oncology International Journal}

Jing Wang et al. [25] reported in his study including 9 irradiated NPC patients among a total of 50 patients, that the proportion of early stage cases in the post-irradiated EAC SCC patients was higher than that in the primary EAC SCC patients. He explained that by the nonspecific symptomatology of the early stage of EACSCC so that early diagnosis of primary EACSCC is difficult to achieve and the fact that post-irradiated patients are more aware of lesions in their radiation field so they may seek evaluation by physicians as soon as possible. Furthermore, the NPC patients presented with more symptoms at initial presentation than did the primary EAC SCC patients which makes it another likely reason so as the NPC patients were diagnosed earlier than the primary EAC SCC patients.

Since it is a rare malignancy, there is no established American Joint Committee on Cancer [AJCC] or Union for International Cancer Control [UICC] staging system for this type of neoplasm so far. Arriaga et al. [26] suggested a staging system in 1990, which has since entered the literature as the Pittsburgh staging system, allowing for a more accurate comparison of treatment and outcomes in patients with this disease. This system underwent minor revision by Moody et al. [2] in 2000. The latter combines the histopathological and radiological findings, leading to a more comprehensive staging of these tumors.

Although several treatment modalities have been described in the literature, there is a lack of consensus as to the best treatment, mainly due to the absence of prospective randomized studies [8].Surgical resection is crucial as a treatment modality, and early surgical intervention is associated with increased survival $[2,9,27]$.

The management of these tumors was initially described by Politzer [28] in 1883. Since then, the management has evolved from piecemeal temporal bone resection to en bloc temporal bone resection and further to combined modality treatment of surgery and post-operative radiation therapy [RT] [9]. In a retrospective analysis of 21 patients, Kollert et al. [29] found that stage- dependent lateral or subtotal TBR combined with parotidectomy as well as a neck dissection was the most beneficial approach.

While some investigators suggest RT for recurrent cases, questionable free margins and/or lymph node metastases [29], most of authors recommend postoperative RT for T3 or T4 tumors in combination with extended temporal bone resection $[30,31]$ and some of them recommend RT systematically to T1 or T2 tumors in adjunct to surgery [32,33]. A retrospective review including 144 patients did not find evidence of improved survival with the addition of RT to TBR [with 48 vs. $44.4 \%$ 5-year survival for TBR + RT vs. TBR alone, respectively] [34]. Jing Wang [25] reported that Adjuvant postoperative RT was not significantly correlated with the overall survival rates but it is unnecessary for early stage EAC SCC, particularly in patients with guaranteed intraoperative tumor-free margins. Our patient has undergone a postoperative RT given the affected resection margins despite the extensive surgical treatment that was performed.

Surgery or radiotherapy alone is usually used for T1 lesion. Ogawa et al. [14] found the 5-year DFS rate in T1, T2 and T3 patients to be 83,45 and $0 \%$ in the RT group $[\mathrm{P}<0.0001]$ and 75,75 and $46 \%$ in the group that underwent surgery with RT $[\mathrm{P}=0.13]$. Based on those results, they recommend radical radiotherapy alone as the treatment of choice for early-stage [T1] disease and surgery with radiotherapy for more advanced [T2-3] disease.

According to Jing Wang [25], the post irradiated EAC SCC patients had received RT for NPC previously, and adjuvant postoperative RT may induce serious complications even over the long term after the first radiotherapy. In his study, 5/9 postirradiated EAC SCC patients received another course of adjuvant RT and three of them developed severe radionecrosis. The high incidence of radiation-induced necrosis in the irradiated EAC SCC patients imposes caution when applying postoperative radiation particularly when it comes to patients with earlystage carcinoma. Accordingly, it is unnecessary to administer adjuvant radiotherapy to patients with early-stage EAC SCC with guaranteed tumor-free margins.

There is conflicting data in the literature regarding the benefits of chemotherapy with or without radiation. While Ogawa et al. [14] did not find chemotherapy to increase disease free survival in any stage of the disease, a multi-institutional review by Yin et al. [13] has suggested increased survival with chemotherapy in stage 3 and 4 disease, if combined with surgery and radiation [ 28.7 vs. $52.5 \%$; surgery + radiation vs. surgery + radiation + chemotherapy]

A number of factors other than the tumors stage, poorly differentiated tumors, [35] lymph node involvement, and facial nerve palsy [36] have been noted to confer poor prognosis. Possible predisposing factors for the disease are preceding head and neck radiation for nasopharyngeal and skin neoplasms [36].

\section{Conclusion}

Post-irradiation EAC SCC has similar symptoms and invades similar regions as its primary counterpart. This entity is usually discovered in the early stage in post-irradiated EAC SCC patients comparing to the primary EAC SCC. Aggressive surgical treatment is strongly recommended, but adjuvant radiotherapy for early stage EAC SCC should be provided cautiously to prevent further radiation induced complications.

\section{Reference}

1. Crabtree JA, Britton BH, Pierce MK (1976) Carcinoma of the external auditory canal. Laryngoscope 86(3): 405-415.

2. Moody SA, Hirsch BE, Myers EN (2000) Squamous cell carcinoma of the external auditory canal: an evaluation of a staging system. Am J Otol 21(4): 582-588. 


\section{Cancer Therapy \& Oncology International Journal}

3. Arena S, Keen M (1988) Carcinoma of the middle ear and temporal bone. Am J Otol 9: 351-356.

4. Leonetti JP, Smith PG, Kletzker GR, et al. (1996) Invasion patterns of advanced temporal bone malignancies. Am J Otol 17(3): 438-442.

5. Lo WC, Ting LL, Ko JY, Chang YL, Wang CP, et al. (2008) Malignancies of the ear in irradiated patients of nasopharyngeal carcinoma. Laryngoscope 118(12): 2151-2155.

6. Koppany Visnyei, Rupinder Gill, Efat Azizi And Bruce Culliney (2013) Squamous cell carcinoma of the external auditory canal: A case report and review of the literature. Oncology Letters 5(5): 1587-1590.

7. A Mazzoni, G Danesi, E Zanoletti (2014) Primary squamous cell carcinoma of the external auditory canal: surgical treatment and longterm outcomes. Acta Otorhinolaryngol Ital 34(2):129-137.

8. Gidley PW (2009) Managing malignancies of the external auditory canal. Expert Rev Anticancer Ther 9(9): 1277-1282.

9. Moffat DA, Wagstaff SA, Hardy DG (2005) The outcome of radical surgery and postoperative radiotherapy for squamous cell carcinoma of the temporal bone. Laryngoscope 115(2): 341-347.

10. Lederman M (1965) Malignant tumours of the ear. J Laryngol Otol 79: 85-119.

11. Kuhel WI, Hume CR, Selesnick SH (1996) Cancer of the EAC and temporal bone. Otolaryngol Clin North Am 26(5): 827-852.

12. Lim LH, Goh YH, Chan YM, Chong VF, Low WK (2000) Malignancy of the temporal bone and external auditory canal. Otolaryngol Head Neck Surg 122(6): 882-886.

13. Yin M, Ishikawa K, Honda K, Arakawa T, Harabuchi Y, et al. (2006) Analysis of 95 cases of squamous cell carcinoma of the external and middle ear. Auris Nasus Larynx 33(3): 251-257.

14. Ogawa K, Nakamura K, Hatano K, Uno T, Fuwa N, et al. (2007) Treatment and prognosis of squamous cell carcinoma of the external auditory canal and middle ear: a multi-institutional retrospective review of 87 patients. Int J Radiat Oncol Biol Phys 68(5):1326-1334.

15. Leonetti JP, Smith PG, Kletzker GR, Izquierdo R (1996) Invasion patterns of advanced temporal bone malignancies. Am J Otol 17(3): 438-442.

16. Barrs DM (2001)Temporal bone carcinoma. Otolaryngol Clin North Am 34(6):1197-1218.

17. Yoon M, Chougule P, Dufresne R, Wanebo HJ (1992) Localized carcinoma of the external ear is an unrecognized aggressive disease with a high propensity for local regional recurrence. Am J Surg 164(6): 574-577.

18. Lim LH, Goh YH, Chan YM, Chong VF, Low WK (2000) Malignancy of the temporal bone and external auditory canal. Otolaryngol Head Neck Surg 122(6): 882-886.

19. Lustig LR, Jackler RK, Lanser MJ (1997) Radiation-induced tumors of the temporal bone. Am J Otol 18(2): 230-235.

20. Nyrop M, Grontved A (2002) Cancer of the external auditory canal. Arch Otolaryngol Head Neck Surg 128(7): 834-837.
21. GarnerFT, Barrs DM, Lanier DM, Carter TE, Mischke RE (1988) Radiationinduced sarcoma of the skull: a case report. Otolaryngol Head Neck Surg 99(3): 326-329.

22. Mark RJ, Bailet JW, Poen J, Fu YS, Parker RG, et al. (1993) Postirradiation sarcoma of the head and neck. Cancer 72(3): 887-893.

23. Beer KT, Buhler SS, Mullis P, Laeng RH, Greiner R (2005) A microcystic adnexal carcinoma in the auditory canal 15 years after radiotherapy of a 12-year-old boy with nasopharynx carcinoma. Strahlenther Onkol 181(6): 405-410

24. Shu MT, Lin HC, Lee JC, Chen BF (2011) Radiation-induced squamous cell carcinoma of the external auditory canal. Otol Neurotol 32(3): e24-e25.

25. Jing Wang, Bingbin Xie, Chunfu Dai (2015) Clinical Characteristics and Management of External Auditory Canal Squamous Cell Carcinoma in Post-Irradiated Nasopharyngeal Carcinoma Patients. Otology, Neurotology 36(6): 1081-1088.

26. Arriaga M, Curtin H, Takahashi H, Hirsch BE, Kamerer DB (1990) Staging proposal for external auditory meatus carcinoma based on preoperative clinical examination and computed tomography findings. Ann Otol Rhinol Laryngol 99(9): 714-721.

27. Austin JR, Stewart KL, Fawzi N (1994) Squamous cell carcinoma of the external auditory canal. Therapeutic prognosis based on a proposed staging system. Arch Otolaryngol Head Neck Surg 120(11): 1228-1232.

28. Politzer A (1883) Textbook of diseases of the ear. London: Bailliere Tindall and Cox pp: 729-734.

29. Kollert M, Draf W, Minovi A, Bockmuhl U (2004) [Carcinoma of the external auditory canal and middle ear: therapeutic strategy and follow up]. Laryngorhinootologie 83(12): 818-823.

30. Zanoletti E, Marioni G, Stritoni P, Martini A, Mazzoni A, et al. (2014) Temporal bone squamous cell carcinoma: analyzing prognosis with univariate and multivariate models. Laryngoscope 124(5): 1192-1198.

31. Rothschild S, Ciernik IF, Hartmann M, Schuknecht B, Lutolf UM, et al. (2009) Cholesteatoma triggering squamous cell carcinoma: case report and literature review of a rare tumor. Am J Otolaryngol 30(4): 256-260.

32. Gidley PW, Roberts DB, Sturgis EM (2010) Squamous cell carcinoma of the temporal bone. Laryngoscope 120(6): 1144-1151.

33. Sugimoto H, Ito M, Hatano M, Kondo S, Suzuki S, et al. (2011) Roles of epithelialYmesenchymal transition in squamous cell carcinoma of the temporal bone. Otol Neurotol 32(3): 483-487.

34. Prasad S, Janecka IP (1994) Efficacy of surgical treatments for squamous cell carcinoma of the temporal bone: a literature review. Otolaryngol Head Neck Surg 110(3): 270-280.

35. Leong SC, Youssef A, Lesser TH (2013) Squamous cell carcinoma of the temporal bone: outcomes of radical surgery and postoperative radiotherapy. Laryngoscope 123(10): 2442-2448.

36. Lobo D, Llorente JL, Suarez C (2008) Squamous cell carcinoma of the external auditory canal. Skull Base 18(3): 167-172. 


\section{Your next submission with Juniper Publishers} will reach you the below assets

- Quality Editorial service

- Swift Peer Review

- Reprints availability

- E-prints Service

- Manuscript Podcast for convenient understanding

- Global attainment for your research

- Manuscript accessibility in different formats ( Pdf, E-pub, Full Text, Audio)

- Unceasing customer service

Track the below URL for one-step submission https://juniperpublishers.com/online-submission.php 